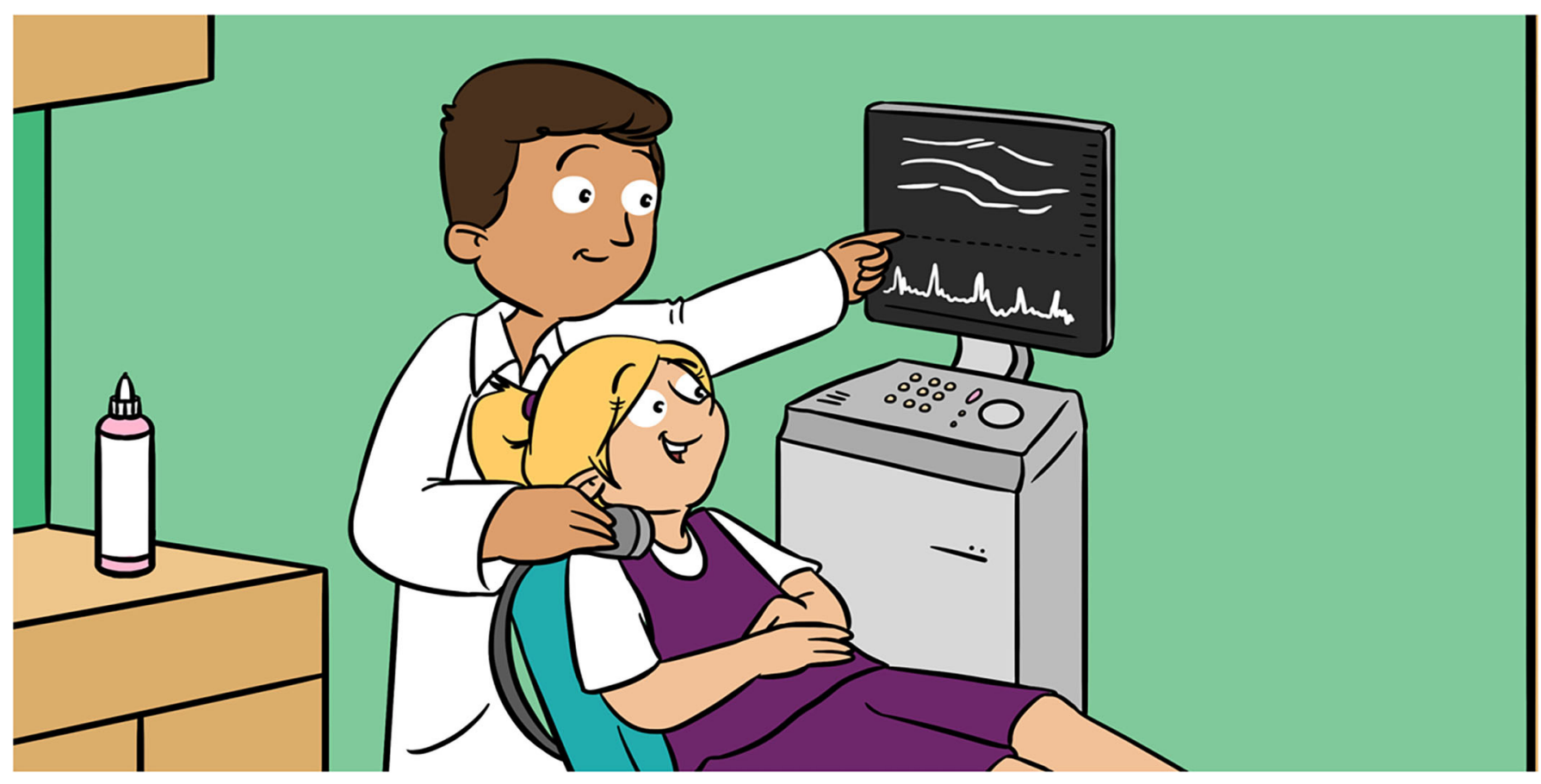

\title{
EXAMINING BLOOD VESSELS USING SOUND WAVES
}

\section{Christine M. Tallon ${ }^{1 *}$, Kurt J. Smith ${ }^{2}$, Nia Lewis ${ }^{3}$ and Ali M. McManus ${ }^{1}$}

${ }^{1}$ Centre for Heart, Lung, and Vascular Health, University of British Columbia, Kelowna, BC, Canada

${ }^{2}$ Cerebrovascular Health, Exercise, and Environmental Research Science (CHEERS) Laboratory, Department of Exercise Sciences, Physical \& Health Education, Faculty of Education, University of Victoria, Victoria, BC, Canada

3 Independent Vascular Services Ltd, Vascular Studies Unit, Warrington Hospital, Warrington and Halton Teaching Hospitals National Health Service (NHS) Foundation Trust, Warrington, United Kingdom

\section{YOUNG REVIEWERS:}

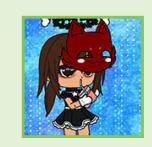

ALEXIA

AGE: 11

$\begin{array}{ll} & \\ \text { AGE: } 9\end{array}$
Your heart works as a team with your body's blood vessels. Your heart pumps the blood, while blood vessels help the blood travel all over your body, just as a garden hose helps move water all around your garden. Blood carries oxygen and other nutrients to your muscles and organs and removes carbon dioxide and other wastes. These are very important chores for the blood! Sometimes doctors need to check whether the heart and blood vessels are working properly, or scientists may want to study how blood vessels work as people get older. To do this, a technique called ultrasound is used to take pictures and videos of the blood vessels and the blood moving through them. But how does sound create pictures? This article will explain how ultrasound works and how it can be used to examine blood vessels and the speed of the blood flow. 


\section{BLOOD AND BLOOD VESSELS HAVE IMPORTANT JOBS}

Just like water traveling through a garden hose in your backyard, blood flows through blood vessels in your body. Blood vessels are the tubes that allow blood to flow out from the heart, around the body, and back to the heart (See more information in "Blood Vessels Under the Microscope" [1]). Blood is made up of four main components: red blood cells, white blood cells, platelets, and plasma-each with important jobs to do! Red blood cells carry oxygen to all your other cells, to fuel them, and they carry carbon dioxide (a waste product) away. White blood cells help your body fight infections. Platelets help to form clots, which plug the holes in blood vessel walls when you get injured. Plasma, made up mostly of water, helps blood cells flow through the blood vessels, just like water through a garden hose. Plasma also transports nutrients and important proteins throughout the body.

Blood vessels make two loops within the body: a small one and a large one (Figure 1). In the small loop, blood that is low in oxygen flows from the heart to the lungs, where it receives oxygen. Blood with high levels of oxygen travels from the lungs back to the heart, ready to be pumped to all other parts of the body along the larger loop. Blood vessels in this large loop range in size, with the largest vessels located closest to the heart and the smallest located furthest away from the heart. The largest blood vessels are the arteries, which have strong muscular walls. The smallest blood vessels are the capillaries, which have thin walls so the blood can easily exchange oxygen, nutrients, and carbon dioxide through them. Veins are blood vessels that carry blood back toward the heart, and they do not have strong muscular walls like arteries.

Because blood vessels are so important for keeping us alive, it is important for doctors and scientists to be able to measure whether they are working properly, particularly as we get older and the blood vessels start to change. One easy method to examine blood vessels involves using sound waves to create images of them, with a technique called ultrasound (For more information see "HOCUS POCUS-Using the magic of ultrasound to look inside the body" [2]). To understand how this technique works, let is first talk about sound waves.

\section{WHAT IS A SOUND WAVE?}

Sound waves are created when an object vibrates the air around it, and that vibration travels through the air, away from the source of the sound, as a wave (Read more about this in "Hear and There: Sounds from Everywhere!" [3]). Sound waves have two important characteristics: wavelength and frequency (Figure 2). Picture ocean waves rising up to a peak before falling to a low point, while also rolling closer to the beach. The space that one sound wave cycle takes as it 


\section{Figure 1}

Blood vessels make two loops within the body. Within the shaded grey box is the small loop, made up of blood vessels that connect the heart to the lungs, where blood can receive oxygen and get rid of carbon dioxide waste. The larger loop is very complex, and it moves blood to and from the heart and all other parts of the body, including the brain, other organs like the liver and kidneys, and the muscles. The figure was created using Mind the Graph platform.

\section{WAVELENGTH}

The space that one sound wave cycle takes as it rolls up and down horizontally.

\section{FREQUENCY}

The number of complete wave cycles occurring in $1 \mathrm{~s}$.

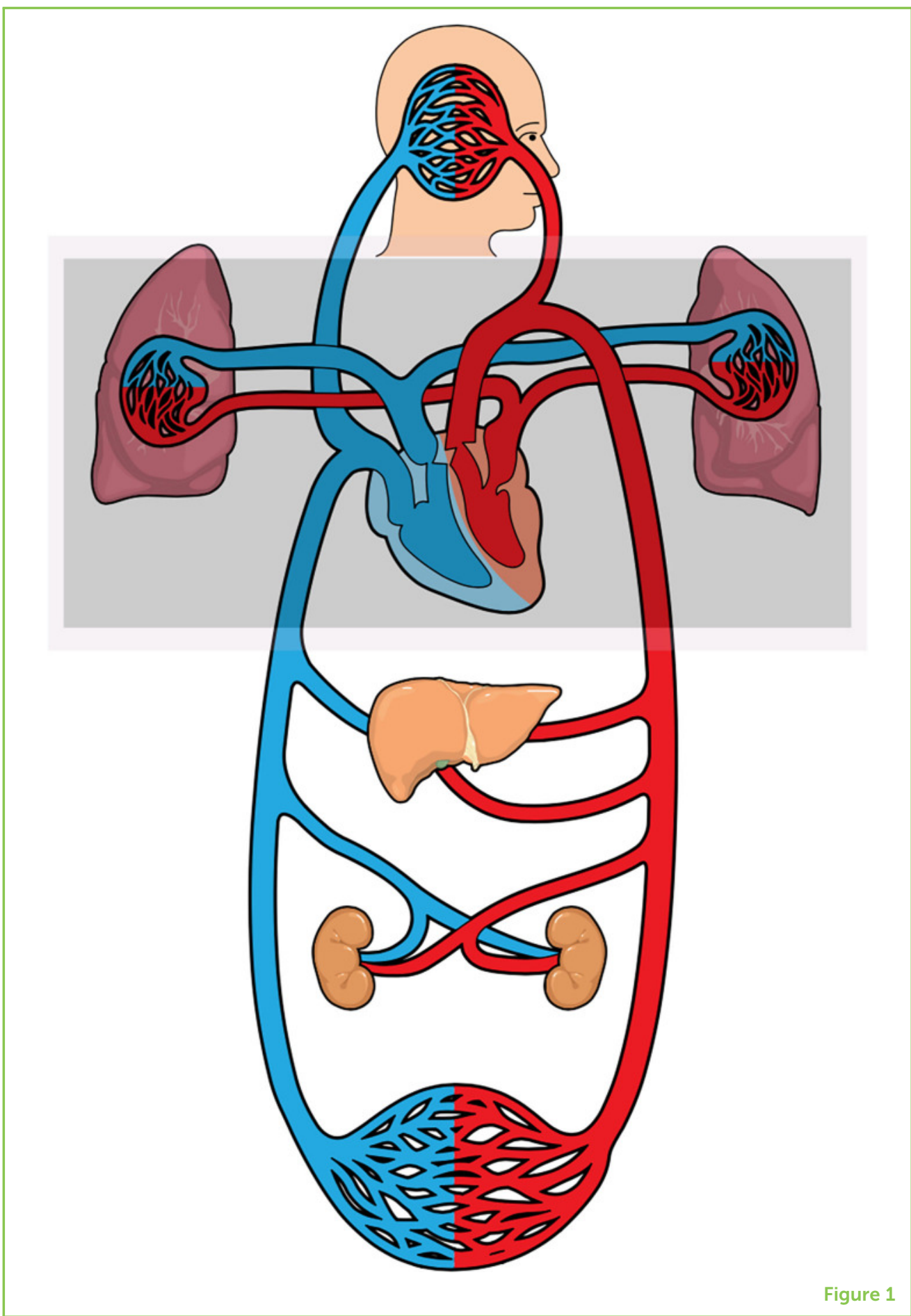

rolls up and down horizontally is called its wavelength. Sound waves can also be measured by their speed, which is known as frequency. The frequency of sound waves is a count of how many complete wave cycles occur in $1 \mathrm{~s}$. Frequency determines the pitch of the sound: high pitch corresponds to high frequency and low pitch to low frequency. Sound waves with higher frequencies have shorter wavelengths. 


\section{Figure 2}

(A) This sound wave has a long wavelength. Long wavelength represents a low frequency sound, which we hear as a lower pitch, like thunder booming in a storm. (B) This sound wave has a shorter wavelength and higher frequency, resulting in a higher pitch, like a whistle in gym class.

\section{HERTZ (HZ)}

The unit for measuring frequency. One $\mathrm{Hz}$ is one complete sound wave or cycle per second.

\section{ULTRASOUND}

Sounds higher than $20,000 \mathrm{~Hz}$

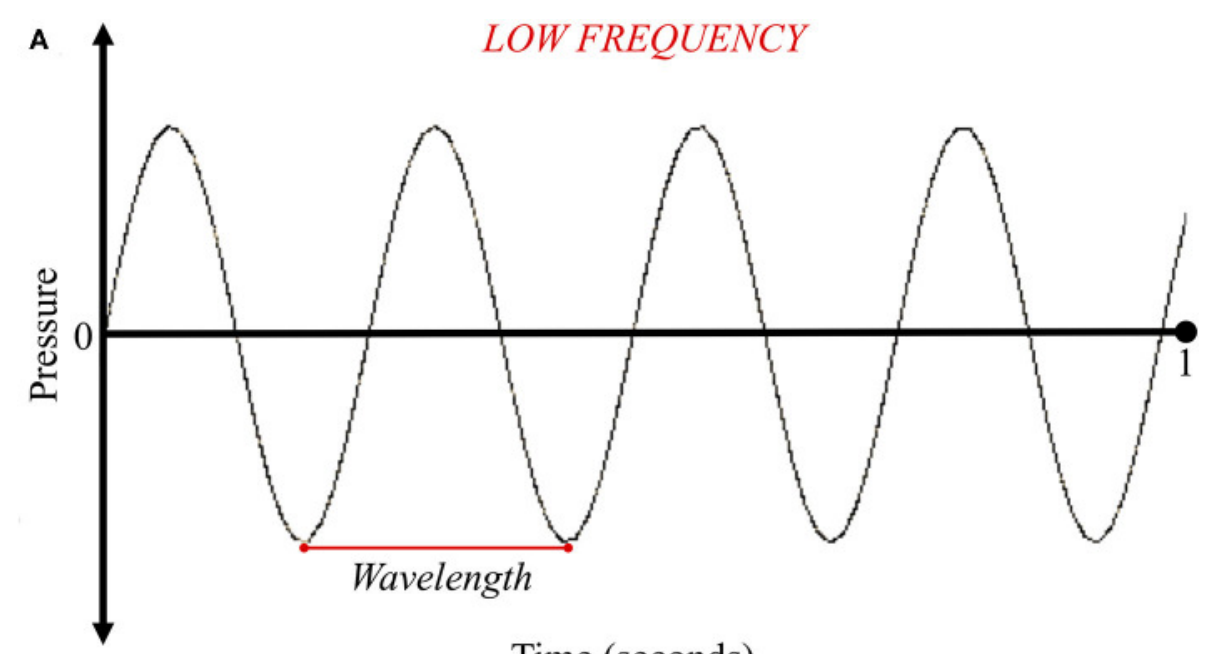

Time (seconds)

B

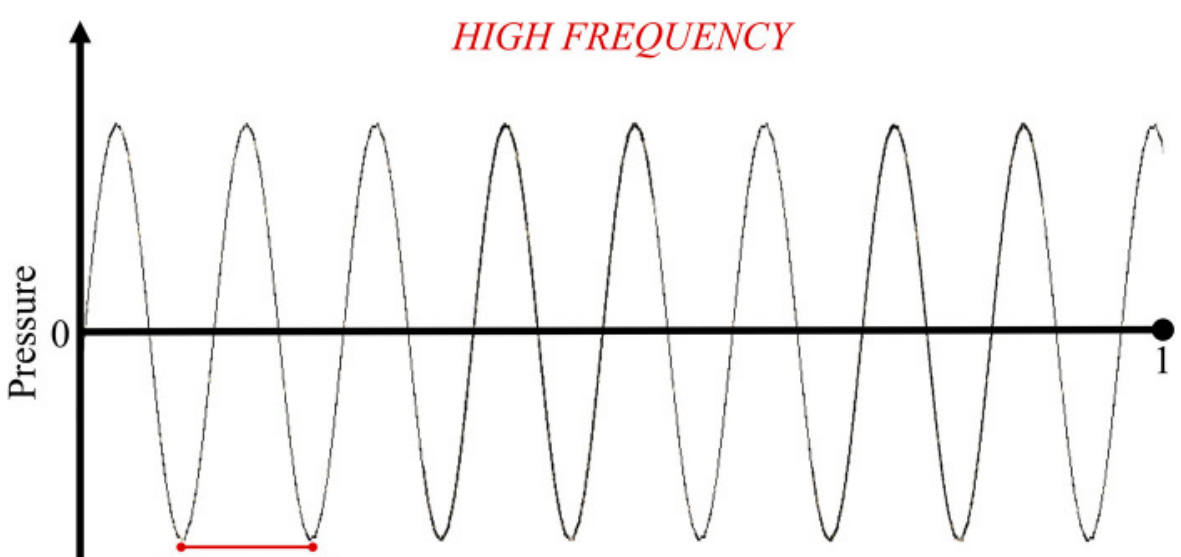

Wavelength

Time (seconds)

The unit for measuring frequency is $\mathrm{Hertz}(\mathrm{Hz})$. One $\mathrm{Hz}$ is one complete sound wave cycle per second. Human ears can only hear sounds between 20 and $20,000 \mathrm{~Hz}$. Sounds $<20 \mathrm{~Hz}$ are called infrasound, while sounds higher than $20,000 \mathrm{~Hz}$ are called ultrasound. Ultrasound is the type of sound used to look inside our bodies. To create images of blood vessels, ultrasound requires sound waves with frequencies of 2-20 megahertz. A megahertz is made up of $1,000,000 \mathrm{~Hz}$ !

\section{HOW CAN WE USE ULTRASOUND TO EXAMINE BLOOD VESSELS?}

When a doctor or scientist wants to look at the blood vessels, an ultrasound machine is used. This machine looks like a computer, with a 
Figure 3

(A) An ultrasound machine sends electrical pulses to the transducer. (B) The pulses stimulate a crystal within the transducer, which converts electrical energy into sound waves that can travel through the skin. (C) When the sound waves meet a tissue, like a blood vessel, they bounce back to the transducer. (D) The crystal in the

transducer converts the sound waves back into electrical pulses, which are displayed on the screen to create an image. (E) The size of the blood vessels and the speed of the blood can be determined from the image.

\section{TRANSDUCER}

\section{A small hand-held} piece of equipment that sends out sound waves and waits for their return.

\section{PIXEL}

Small pieces of an ultrasound image on a screen. The location of each pixel on the screen is based upon the time it takes for the sound wave to return to the transducer.

\section{ATTENUATION}

The decrease in strength of a sound wave based on the distance it travels.

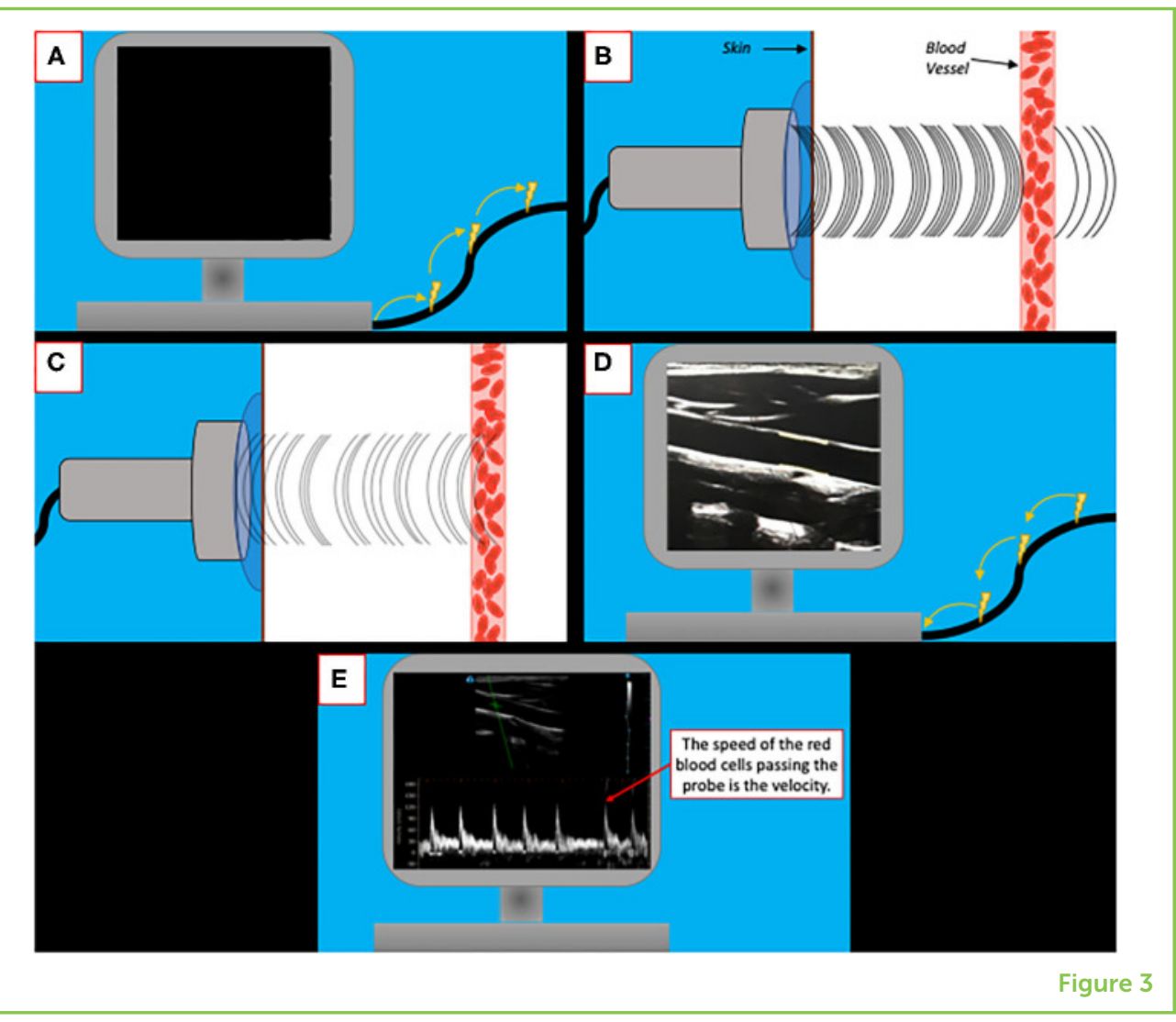

display screen and a small hand-held device called a transducer. The transducer sends out sound waves and waits for their return (Figure 3). Information from the returning waves is used to create the image. But how?

An ultrasound image is made up of a variety of pixels, like those of an image from your favorite video game. The location of each pixel on the screen is based upon the time it takes for the sound wave to return to the transducer. The deeper the sound wave travels into the body, the more time it will take for it to return, causing the pixel to be placed near the bottom of the screen. In comparison, a sound wave that does not have to travel as far will return to the transducer faster and be placed near the top of the image.

As a sound wave travels through the body, the strength of the wave decreases with the distance traveled, in a process called attenuation. Think of a time you have gone swimming, running, or walking. The farther you go, the more tired you become. Similarly, a sound wave loses strength the farther it travels from the transducer. Sound waves that travel only a short distance and experience minimal attenuation will appear as brighter, whiter pixels on the image, while sound waves that travel farther, and experience large amounts of attenuation will appear as duller and darker pixels on the screen. 
Examining blood vessels using ultrasound can help doctors diagnose certain problems. For instance, increased blood flow can might mean that there is an infection. When blood flow is slower than normal this might mean that the blood vessels are getting narrower or even becoming blocked. These images of the blood vessels and the speed of the blood flow that ultrasound measures can tell doctors and scientists about the health of the blood vessel wall, and whether there are any health problems. When we are young it is rare a doctor might want to use ultrasound to image our blood vessels. More common is for a scientist to use ultrasound to study how blood vessels function. These studies provide an opportunity for scientists to compare blood vessels between children and adults. It is more common for a doctor to want to measure our blood vessels when we are older. When we get older the walls of our blood vessels can become weaker and there can be a higher risk of having blockages within the vessels. Eating a healthy diet can help protects us against blockages and being physically active can help keep the walls of our blood vessels strong.

\section{VELOCITY}

The speed the blood is moving.

\section{HOW CAN WE MEASURE THE SPEED OF THE BLOOD?}

Sometimes doctors need to know about the velocity (speed) of the blood moving through a patient's vessels. Knowing the velocity of the blood allows doctors and scientists to calculate the amount of blood flowing through a blood vessel over a unit of time. This is important because the amount of blood flowing can be a sign the heart is pumping properly and that there are no blockages in the system. A special type of ultrasound called Doppler ultrasound can be used to measure this, using principles of the Doppler effect [4, 5]. To understand the Doppler effect, think about an ambulance traveling toward you with its siren blaring. The sound of the siren gets louder and higher pitched (higher frequency) as it approaches you. As the ambulance passes you and gets farther away, the siren gets quieter and lower pitched (lower frequency). This is due to the Doppler effect: an increase or decrease in the frequency of a sound as the source moves toward or away from the observer. In Doppler ultrasound, the speed of the red blood cells flowing past the sound waves changes the frequency of the reflected sound waves that are received by the transducer. This change in frequency can be used to calculate the blood velocity.

\section{ULTRASOUND OF BLOOD VESSELS HELPS TO KEEP PEOPLE HEALTHY!}

The heart and the blood vessels support the functions of the entire body. As we grow and age, blood vessels grow and age, too. It is important to maintain a healthy heart and blood vessels as we age. If we do not take steps to keep them healthy, blood vessel walls can become stiff, making it harder for the blood to move through the body. 
Ultrasound is one of the techniques doctors and scientists can use to examine whether the blood vessels are healthy. Ultrasound can answer many questions, such as, "Are the walls of the blood vessels strong and healthy?"; "How much blood is being pumped by the heart through the blood vessels?"; and "Are the blood vessels blocked?"

Scientists can use ultrasound of blood vessels to better understand whether our daily activities, such as exercising or sitting, change either the blood vessels or the velocity of the blood. For example, the amount of blood flowing to the brain was found to decrease when adults do not take regular breaks from sitting (Find more information in "Taking Regular Breaks From Sitting Prevents Reductions in Brain Blood Flow" [6]). We can all do things to keep our blood vessels working properly! Regular exercise helps blood vessels to stay healthy, by increasing the amount of blood flowing through the vessels. This helps strengthen the vessel walls. Poor eating habits, such as a diet containing excess saturated fats and high levels of refined sugar, could lead to stiffer blood vessel walls, which increases the difficulty the heart faces to pump blood and is a precursor to vascular disease [7]. Saturated fats are mainly found in fatty meats, butter, cheese, and also in some plant-based oils such as coconut oil. Try eating low fat cheese and cook with plant oils like olive oil and not butter. Refined sugar is the white sugar we often used to bake, but is also found in many other things we eat and drink like sodas, fruit yogurt, ice-cream, candies, cookies and even French fries. We do not have to cut these out of diets, just make them special treats that you have occasionally and instead choose whole grains, low sugar breakfast cereals or plain yogurt with real fruit. Together, regular exercise, a healthy diet, and ultrasound technology can help us maintain the health of our blood vessels throughout our entire lives.

\section{REFERENCES}

1. Machado, M., Mitchell, C., Franklin, J., Thorpe, A., and Rutland, C. 2020. Blood vessels under the microscope. Front. Young Minds. 8:151. doi: 10.3389/frym.2019.00151

2. El-Baba, M., Jamnik, J., Heslop, C. 2020. Hocus POCUS-using the magic of ultrasound to look inside the body. Front. Young Minds. 8:66. doi: 10.3389/frym.2020.00066

3. Henning, D., Sabic, E., Hout, M. 2018. Hear and there: sounds from everywhere! Front. Young Minds. 6:63. doi: 10.3389/frym.2018.00063

4. Williams, D. 2012. The physics of ultrasound. Anaesth Intensive Care Med. 13:264-8. doi: 10.1016/j.mpaic.2012.03.010

5. Martin, D. J., Wells, I. T. P., and Goodwin, C. R. 2015. Physics of ultrasound. Anaesth Intensive Care Med. 16:132-5. doi: 10.1016/j.mpaic.2015.01.003

6. Carter, S., Holder, S., Thijssen, D., Hopkins, N. 2019. Taking regular breaks from sitting prevents reductions in brain blood flow. Front. Young Minds. 7:77. doi: 10.3389/frym.2019.00077 
7. Kohn, J. C., Lampi, M. C., and Reinhart-King, C. A. 2015. Age-related vascular stiffening: causes and consequences. Front Genet. 6:112. doi: 10.33 89/fgene.2015.00112

SUBMITTED: 17 October 2020; ACCEPTED: 06 September 2021; PUBLISHED ONLINE: 11 October 2021.

EDITED BY: Viduranga Y. Waisundara, Australian College of Business and Technology, Sri Lanka

CITATION: Tallon CM, Smith KJ, Lewis N and McManus AM (2021) Examining Blood Vessels Using Sound Waves. Front. Young Minds 9:618465. doi: 10.3389/ frym.2021.618465

CONFLICT OF INTEREST: NL was employed by company Independent Vascular Services Ltd.

The remaining authors declare that the research was conducted in the absence of any commercial or financial relationships that could be construed as a potential conflict of interest.

COPYRIGHT @ 2021 Tallon, Smith, Lewis and McManus. This is an open-access article distributed under the terms of the Creative Commons Attribution License (CC BY). The use, distribution or reproduction in other forums is permitted, provided the original author(s) and the copyright owner(s) are credited and that the original publication in this journal is cited, in accordance with accepted academic practice. No use, distribution or reproduction is permitted which does not comply with these terms.

\section{YOUNG REVIEWERS}

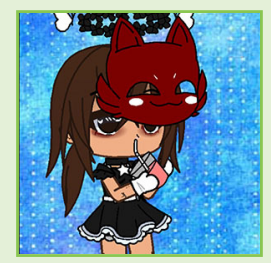

\section{ALEXIA, AGE: 11}

I enjoy talking to my friends whenever I can. I love to read science-fiction. When I am older, I want to be an engineer or inventor. I also like making YouTube videos and watching anime.

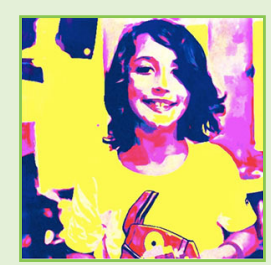

\section{VICTOR, AGE: 8}

Victor is a highly motivated kid that is remarkably talented. He has been always in the gifted program and his love of science has emerged from a very early age. He is very talented in math and he has developed an intense interest in microbes. He said that he wants to work on a COVID vaccine which will contain white blood cells and nutrients to save the world from this pandemic. 

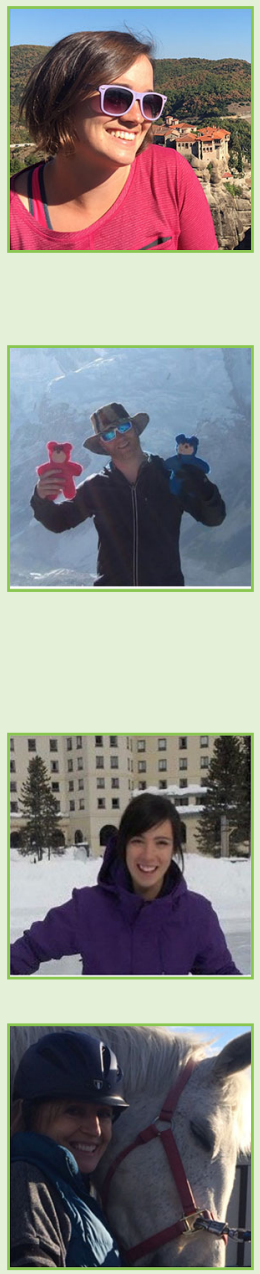

\section{AUTHORS}

\section{CHRISTINE M. TALLON}

Christine Tallon is a Ph.D. candidate at the University of British Columbia in Kelowna, Canada. She is a graduate student within the Pediatric Exercise Research Lab, where her research has focused on brain blood flow and blood vessel function in children. When she is not involved in research, Christine likes to spend time camping, playing sports, and adventuring with her dog. * christinemtallonagmail.com

\section{KURT J. SMITH}

Kurt is an assistant professor at the University of Illinois in Chicago, USA. His research in the Integrative Physiology Laboratory as part of the Department of Kinesiology and Nutrition focuses on measuring brain blood flow and blood vessel function at rest and during exercise, in healthy and diseased populations. When Kurt and his wife are not bringing their three energetic daughters into the laboratory or on high-altitude research expeditions, they are surfing, skiing, or rock climbing.

\section{NIA LEWIS}

Nia Lewis is a clinical vascular scientist at Independent Vascular Services in the United Kingdom. Nia uses ultrasound to examine blood vessel health and diagnose disease. In her spare time, Nia likes to hike the hills in Wales and spend time with her family.

\section{ALI M. MCMANUS}

Ali is a professor of pediatric exercise physiology at the University of British Columbia in Kelowna, Canada. She directs the Pediatric Exercise Research Laboratory, which is focused on understanding how various environmental challenges like exercise, sitting, or traveling to high-altitude affect how the child's body gets oxygen from the air to their brain and skeletal muscles. When she is not working, Ali likes to ride her horse in the backcountry with her dog Milly and have outdoor adventures with her family. 